Article

\title{
Fabrication and Characteristic of a Double Piezoelectric Layer Acceleration Sensor Based on Li-Doped ZnO Thin Film
}

\author{
Chunpeng Ai, Xiaofeng Zhao, Sen Li, Yi Li, Yinnan Bai and Dianzhong Wen * \\ Key Laboratory of Electronics Engineering College of Heilongjiang Province, Heilongjiang University, \\ Harbin 150006, Heilongjiang Province, China; aichunpeng@hlju.edu.cn (C.A.); zhaoxiaofeng@hlju.edu.cn (X.Z.); \\ 2161311@s.hlju.edu.cn (S.L.); 2171256@s.hlju.edu.cn (Y.L.); 2141207@s.hlju.edu.cn (Y.B.) \\ * Correspondence: wendianzhong@hlju.edu.cn; Tel.: +86-0451-86608413
}

Received: 9 April 2019; Accepted: 16 May 2019; Published: 17 May 2019

check for updates

\begin{abstract}
In this paper, a double piezoelectric layer acceleration sensor based on Li-doped ZnO (LZO) thin film is presented. It is constituted by $\mathrm{Pt} / \mathrm{LZO} / \mathrm{Pt} / \mathrm{LZO} / \mathrm{Pt} / \mathrm{Ti}$ functional layers and a Si cantilever beam with a proof mass. The LZO thin films were prepared by radio frequency (RF) magnetron sputtering. The composition, chemical structure, surface morphology, and thickness of the LZO thin film were analyzed. In order to study the effect of double piezoelectric layers on the sensitivity of the acceleration sensor, we designed two structural models (single and double piezoelectric layers) and fabricated them by using micro-electro-mechanical system (MEMS) technology. The test results show that the resonance frequency of the acceleration sensor was $1363 \mathrm{~Hz}$. The sensitivity of the double piezoelectric layer was $33.1 \mathrm{mV} / \mathrm{g}$, which is higher than the $26.1 \mathrm{mV} / \mathrm{g}$ of single piezoelectric layer sensitivity, both at a resonance frequency of $1363 \mathrm{~Hz}$.
\end{abstract}

Keywords: cantilever beam; MEMS technology; Li-doped ZnO thin film; double piezoelectric layer; acceleration sensor

\section{Introduction}

At present, the development of sensor technology has attracted worldwide attention and has been noted as a key technology related to the global economy and scientific and technological progress [1-3]. Work on sensors based on micro-electro-mechanical system (MEMS) technology has developed very rapidly, and has become a research hotspot and focus in related fields, including industry [4], agriculture [5], national defense [6], aerospace [7], transportation [8], family services [9], and other fields. As very important inertial sensors, acceleration sensors are extensively used in the military [10] and industrial [4] and commercial applications [11]. Piezoelectric acceleration sensors, also important, are widely used in many applications, such as flexible devices [11,12], structural health monitoring [13], seismic exploration [14], and biomedical products [15].

As a third-generation semiconductor with advantages, including a wide band gap [16], high transmittance [17], nontoxicity [18], and high radiation hardness [7], $\mathrm{ZnO}$ has a wide range of applications in gas sensors [19-21], nanogenerators [22-25], data storage (memory) application [26,27], and acceleration sensors $[11,28,29]$. Compared with other piezoelectric materials, in addition to its nontoxicity, $\mathrm{ZnO}$ is also compatible with the integrated circuit (IC) process [30]. Wang et al. reported a piezoelectric acceleration sensor based on MEMS technology, in which ZnO nanowires were grown on cellulose paper as a piezoelectric layer by the hydrothermal method. The substrate was two parallel cantilever beams, and a paper mass block was connected at the ends of the two cantilevers. The resonance frequency of the acceleration sensor was $84.75 \mathrm{~Hz}$ and the sensitivity was $16.3 \mathrm{mV} / \mathrm{g}$ [31]. Wong et al. presented large frequency bandwidth $\mathrm{ZnO}$-based single cantilever beam 
structure acceleration sensors by using radio frequency magnetron sputtering, and the sensitivity reached $363.09 \Omega / \mathrm{V}$ [18]. Raaja et al. proposed a simple analytical model for deflection, voltage, and charge sensitivity of a $\mathrm{ZnO}$ piezoelectric accelerometer based on a cantilever beam structure applied to structural health monitoring, and validated the model under different conditions by the finite element method. Voltage sensitivity and charge sensitivity were $60 \mathrm{mV} / \mathrm{g}$ and $2.4 \mathrm{pC} / \mathrm{g}$, respectively [13]. Based on the above research, it is proved that $\mathrm{ZnO}$ has a good application in the MEMS acceleration sensor, and it also reveals that $\mathrm{ZnO}$ has a good compatibility with the MEMS technology. Meanwhile, acceleration sensors fabricated by MEMS technology have the advantages of miniaturization, integration, and easy packaging. At the same time, the piezoelectric constant of pure $\mathrm{ZnO}$ is limited, and it can be enhanced by doping Li impurities [29]. In order to improve the performance of the device, a multi-piezoelectric layer structure has been reported. Zou et al. presented novel single and triaxis piezoelectric-bimorph accelerometers, which built on parylene beams with $\mathrm{ZnO}$ films. The unamplified sensitivities of the $x-, y$-, and $z$-axis were $0.93,1.13$, and $0.88 \mathrm{mV} / \mathrm{g}$ and the cross-axial sensitivity was less than $15 \%$ [32]. Nagano et al. reported a piezoelectric tunable capacitor based on double-layered AlN thin films. The results showed a leakage current of less than $5 \times 10^{-5} \mathrm{Am}^{-2}$ in $500 \mathrm{~nm}$ thick AlN films up to $30 \mathrm{~V}$ [33]. Kanda et al. studied an energy harvester based on multi-layer PZT (Lead zirconate titanate). The fabricated devices with the footprint of $10 \mathrm{~mm} \times 10 \mathrm{~mm}$ was found to provide a high output power of $53.7 \mu \mathrm{W}$ per gravitational acceleration [34]. The multilayered piezoelectric thin films structure can be equivalent to two capacitors in a series, so the output voltage can be doubled and the voltage sensitivity of the sensors can be doubled.

In our previous work, we designed a $\mathrm{ZnO}$ acceleration sensor based on a single piezoelectric layer cantilever structure by doping Li atoms as impurities to increase the resistivity of the $\mathrm{ZnO}$ thin film, thereby enhancing its piezoelectric characteristics. The sensitivity could reach $29.48 \mathrm{mV} / \mathrm{g}$ [29], based on the above reports [32-34]. In order to improve the voltage sensitivity of the acceleration sensor, a series structure double piezoelectric layer acceleration sensor based on the piezoelectric effect of the Li-doped $\mathrm{ZnO}$ thin film was designed, fabricated, and analyzed in this study. The application target is health detection of lathe tools in digital lathes.

\section{Basic Structure and Working Principle}

\subsection{Basic Structure}

As shown in Figure 1, we present two structural models: Single and double piezoelectric layer structures, called model I and model II, respectively. They consist of Pt/Li-doped ZnO (LZO)/Pt/Ti thin films grown on a $\mathrm{SiO}_{2} / \mathrm{Si}$ cantilever beam substrate with a proof mass at the end. A Ti thin film was placed as a transition layer to ensure that the $\mathrm{Pt}$ and $\mathrm{SiO}_{2}$ layers were bonded closely. A Pt thin film was utilized as top, middle (in model II), and bottom electrodes (TE, ME, and BE). Model I is a typical single piezoelectric sandwich structure, and model II is a double piezoelectric layer structure. In model II, LZO thin films were placed among the electrodes to form a series structure in order to increase output voltage sensitivity. In Figure $1, l_{c}, w_{c}$, and $h_{c}$ refer to the length, width, and height of the cantilever beam, respectively, and $l_{m}, w_{m}$, and $h_{m}$ are the length, width, and height of the mass block, respectively.

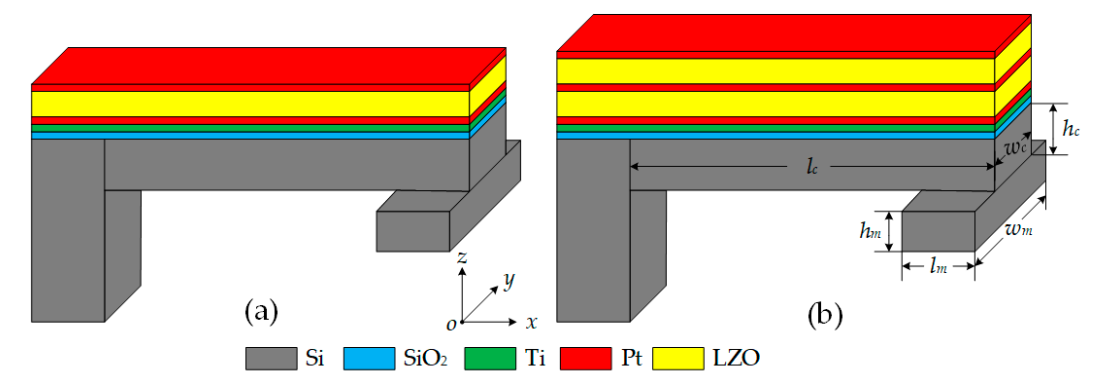

Figure 1. Basic structure of proposed acceleration sensor in two models: (a) Model I; (b) model II. 
The 1st mode resonant frequency of the cantilever beam can be expressed as [35-37]:

$$
f=\frac{1.875}{2 \pi} \sqrt{\frac{0.236 E I}{\left(l_{c}-l_{m} / 2\right)^{3}\left(0.236 \rho h_{c} w_{c}\left(l_{c}-\frac{l_{m}}{2}\right)+\rho h_{c} w_{c} \frac{l_{m}}{2}+\rho h_{m} w_{m} l_{m}\right)}}
$$

where, $E$ is the modulus of elasticity, $I$ is the area moment of inertia about the neutral axis, $\rho$ is the density of $\mathrm{Si}$. It can be seen that $l_{c}$ is inversely proportional to the $f$ frequency of the cantilever beam, and the change of $l_{c}$ has a greater impact on $f$.

The sensor was designed for the health detection of the lathe tool (SNR-0020R-16), the lathe tool's resonance frequency is about $1300 \mathrm{~Hz}$. On the premise of ensuring that the sensor can be installed on the lathe tool normally, meanwhile, in order to guarantee the requirement of sensitivity, we designed the $w_{c}$ to be $2400 \mu \mathrm{m}$; considering that under the action of the mass, the irreversible bending of the cantilever beam will occur when $h_{c}$ is too small, therefore, $h_{c}$ is designed to be $80 \mu \mathrm{m}$, and the size of proof mass is $1000 \mu \mathrm{m} \times 2700 \mu \mathrm{m} \times 395 \mu \mathrm{m}$. In this design, $f$ is controlled by changing the value of $l_{c}$. Figure 2 shows the ANSYS simulation curve of resonance frequency varying with $l_{c}$. When the beam length is $6000 \mu \mathrm{m}$, the resonance frequency is $1327.7 \mathrm{~Hz}$, which is close to that of the lathe tool. The cantilever beam is designed to be $6000 \mu \mathrm{m} \times 2400 \mu \mathrm{m} \times 80 \mu \mathrm{m}$ in size.

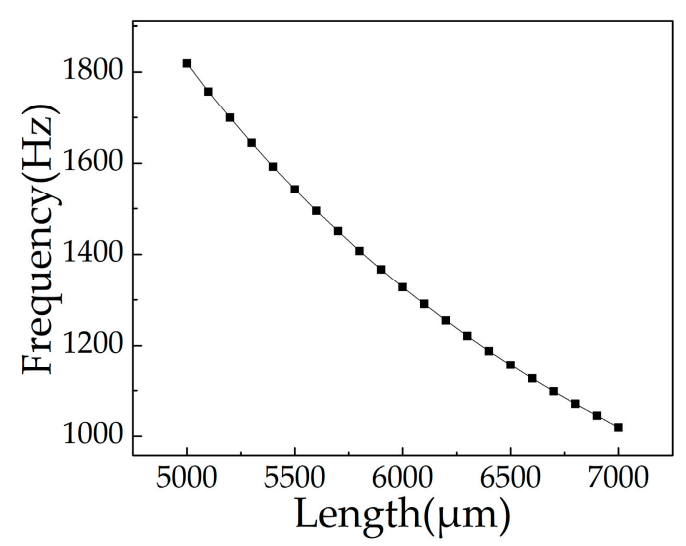

Figure 2. The ANSYS simulation curve between resonance frequency and length of cantilever beam.

\subsection{Working Principle}

Figure 3 shows the operating principle of the proposed acceleration sensor. With applied acceleration, the force $(F)$ produced by the mass block acts on the tip of the cantilever beam, causing deformation of the cantilever beam (Figure 3a). Figure $3 b$ shows the operating principle of the multilayer structure; $d_{1}$ and $d_{2}$ are the thickness of the lower and upper LZO thin films (LZO I and LZO II), respectively. Normally, without the action of external acceleration, the center of the positive and negative charges of the LZO thin film will coincide with each other, and the whole LZO thin film will be electrically neutral when external acceleration along the $z$-axis acts on the cantilever beam. The force produced by the mass block causes deformation of the cantilever beam, and the centers of the positive and negative charges are separated, which leads to positive and negative charges appearing on the top and bottom sides of the LZO thin film. Therefore, the LZO thin film can be equivalent to a capacitor. In the double piezoelectric layer structure, the charges generated by deformation on both sides of the ME are neutralized with each other and the total charge $q$ remains unchanged. The double piezoelectric layer structure can be equivalent to the double capacitor series mode, which is given in Figure $3 b$, and the total capacitance is $C_{d}$. $V_{\text {out1 }}$ is the output voltage between $\mathrm{ME}$ and $\mathrm{BE}$, and the sensor works as model I. $V_{\text {out2 }}$ is the output voltage between TE and $\mathrm{BE}$, and the sensor works as model II. 


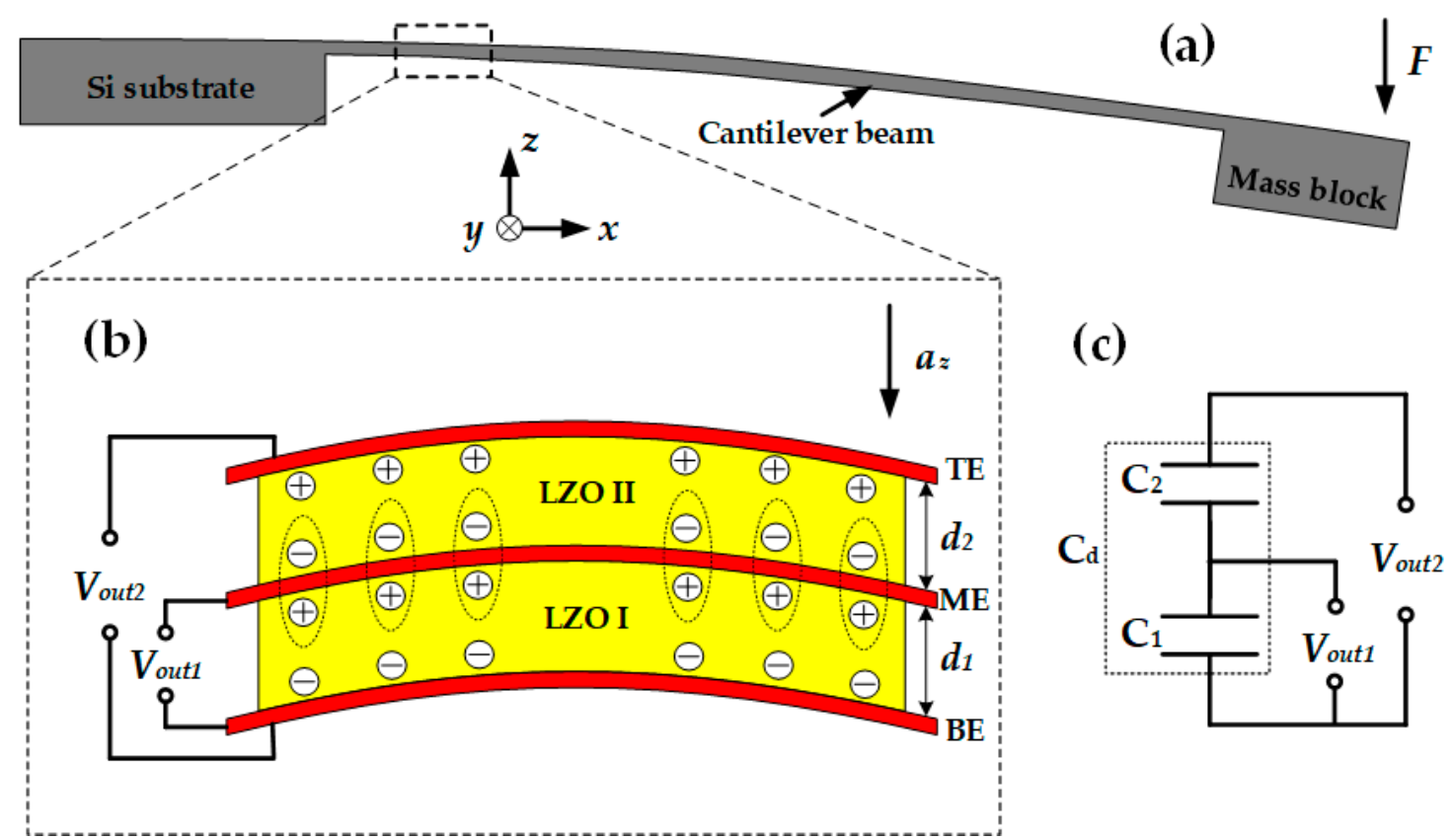

Figure 3. Operating principle of proposed acceleration sensor: (a) Deformation of cantilever beam under the action of $F$; (b) operating principle of double piezoelectric layer; (c) equivalent circuit of double piezoelectric layer.

Based on the elastic mechanism analysis of the cantilever beam [29], the stress $\sigma$ of the cantilever beam is

$$
\sigma=\frac{6 F}{w_{c} h_{c}^{2}} l_{c}
$$

According to the piezoelectric effect, the relationship between the output charge $q$ and the stress $\sigma$ is:

$$
\left(\begin{array}{l}
q_{1} \\
q_{2} \\
q_{3}
\end{array}\right)=\left(\begin{array}{lll}
d_{11} & \cdots & d_{16} \\
d_{21} & \cdots & d_{26} \\
d_{31} & \cdots & d_{36}
\end{array}\right)\left(\begin{array}{c}
\sigma_{1} \\
\vdots \\
\sigma_{6}
\end{array}\right)
$$

where $q_{1}, q_{2}$, and $q_{3}$ denote the charges that appear on the surface of the LZO thin film that are perpendicular to the $x$-axis, $y$-axis, and $z$-axis, respectively; and $d_{11}$ to $d_{16}, d_{21}$ to $d_{26}$, and $d_{31}$ to $d_{36}$ are the piezoelectric coefficients in all directions. In accordance with small deflection theory, $\sigma_{1}, \sigma_{2}$, and $\sigma_{3}$ are for normal stress, and $\sigma_{4}, \sigma_{5}$, and $\sigma_{6}$ are for shear stress. Therefore, in this case, $\sigma_{2}$ to $\sigma_{6}$ was 0 . Equation (3) can be simplified as:

$$
q_{3}=d_{31} \sigma_{1}
$$

Substituting Equation (4) into Equation (2), we get the following equation:

$$
q_{3}=d_{31} \frac{6 F}{w_{c} h_{c}^{2}} l_{c}
$$

It can be seen in Equation (5) that $q_{3}$ is proportional to $F$ when $w_{c}, h_{c}$, and $L_{c}$ of the cantilever beam and $d_{31}$ of the piezoelectric layer are constant.

The sensitivity of the sensor can be expressed as:

$$
S=\frac{V}{a}=\frac{q_{3}}{a C}
$$

According to Newton's Second Law:

$$
F=m a
$$


Therefore, Equation (6) can be written as:

$$
S=\frac{6 d_{31} m l_{c}}{w_{c} 3 h_{c}^{2} C}
$$

where $m$ is the mass of the mass block, $V$ is the output voltage of the sensor, and $a$ is acceleration.

In model I, the capacitance of the single piezoelectric layer can be expressed as:

$$
C_{s}=\frac{\varepsilon_{0} \varepsilon_{r} S}{d_{1}}
$$

where $S$ is the area of the electrode, $\varepsilon_{0}$ is vacuum permittivity, and $\varepsilon_{r}$ is relative permittivity.

For model II, charges that appear on the upper and lower sides of the ME will neutralize each other, and the ME can be regarded as a metal sheet inserted into the parallel plate capacitor. The dielectric constant of the metal is infinite, thus the capacitance of the double piezoelectric layer is:

$$
C_{d}=\frac{\varepsilon_{0} \varepsilon_{r} S}{d_{1}+d_{2}}
$$

Supposing $d_{1}$ equals $d_{2}$, here we have

$$
C_{s}=2 C_{d}
$$

According to Equations (8) and (11), we can define the sensitivity of the single piezoelectric layer acceleration sensor as $S_{s}$ and the double piezoelectric layer as $S_{d}$, and their relationship is:

$$
S_{d}=2 S_{s}
$$

Based on Equation (12), under ideal conditions, theoretical analysis shows that when the thickness of two LZO thin films is equal, $S_{d}$ should be twice as much as $S_{s}$.

\section{Fabrication Technology}

The chips were fabricated on n-type $<100>$ orientation silicon wafers by MEMS technology. Figure 4 shows the main fabrication process. First, the silicon wafers were cleaned by the standard RCA (Radio Cooperation of America) process, after which $\mathrm{SiO}_{2}$ layers were grown on both sides of the wafers by thermal oxidation (Figure 4a). Before deposition, the chamber was pumped to a base pressure of $6.0 \times 10^{-4} \mathrm{~Pa}$, and a presputtering process was followed for $30 \mathrm{~min}$ to clean the target surface and remove any possible contamination in each sputtering process. A Ti layer was then deposited as a transition layer by direct current (DC) magnetron sputtering with $100 \mathrm{~W}$ power for $5 \mathrm{~min}$, argon flow rate of $20 \mathrm{sccm}$ (Standard-state cubic centimeter per minute), and working pressure of $1 \mathrm{~Pa}$ (JGP-DZS, Shenyang Sky Technology Development Co. Ltd., Shenyang, China). A Pt layer (BE) was deposited on the Ti thin film by radio frequency (RF) magnetron sputtering, sputtered for $15 \mathrm{~min}$ at $100 \mathrm{~W}$ power, with the same argon flow rate and working pressure as the Ti layer. Lift-off technology was used to enable the formation of a Ti/Pt electrode pattern (Figure $4 \mathrm{~b}$ ). A $5 \mathrm{wt} \% \mathrm{LZO}$ target was adopted to prepare LZO I thin film by RF magnetron sputtering with $200 \mathrm{~W}$ power for 2 hours under pressure of $1 \mathrm{~Pa}$, with a ratio of oxygen to argon of $5: 20 \mathrm{sccm}$. The graphical process of the LZO I thin film was the same as Ti/Pt (Figure 4c). Sputtering ME (Pt), LZO II layer, and TE (Pt) were under the same conditions as above, and used the same technology for graphical processing (Figure $4 \mathrm{~d}-\mathrm{f}$ ). After the electrodes and piezoelectric layers were fabricated, the upper surface of the silicon wafer was etched by lithography and inductively coupled plasma (ICP) etching technology to form a cantilever beam pattern (Figure $4 \mathrm{~g}$ ), and the lower surface of the silicon wafer was etched by lithography and ICP etching technology to release the cantilever beam structure (Figure $4 \mathrm{~h}$ ). In this way, the acceleration sensor based on the MEMS technology was fabricated. 


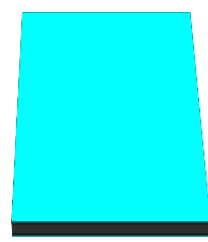

(a)

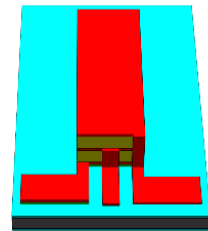

(f)

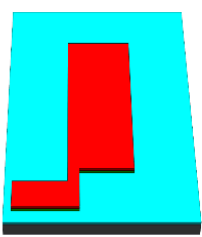

(b)

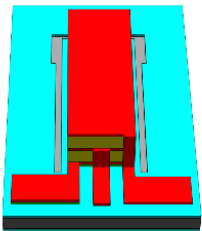

(g)

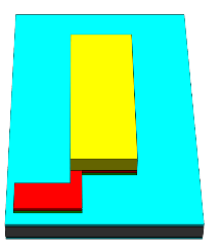

(c)

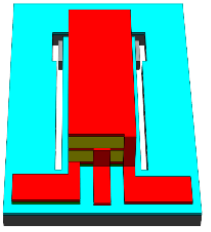

(h)

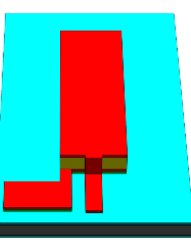

(d)

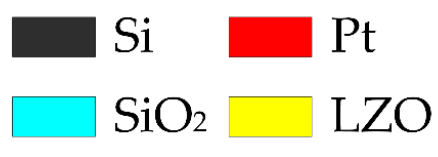

Figure 4. Main fabrication process of the chip: (a) Growing $\mathrm{SiO}_{2}$; (b) depositing Ti/Pt; (c) sputtering Li-doped ZnO (LZO) I; (d) depositing Pt; (e) sputtering LZO II; (f) depositing Pt; (g) etching on the top side; (h) releasing cantilever beam.

As shown in Figure 5, the chip of the proposed sensor was fixed on the printed circuit board (PCB). Holes were made in the PCB below the cantilever beam to make sure the proof mass could move up and down freely when the cantilever beam was deformed. The chip size was $9400 \mu \mathrm{m} \times 5800 \mu \mathrm{m}$. Chip electrodes were connected with the PCB pads by a chip press welder (KNS4526, Kullicke \& Soffa, Haifa, Israel).
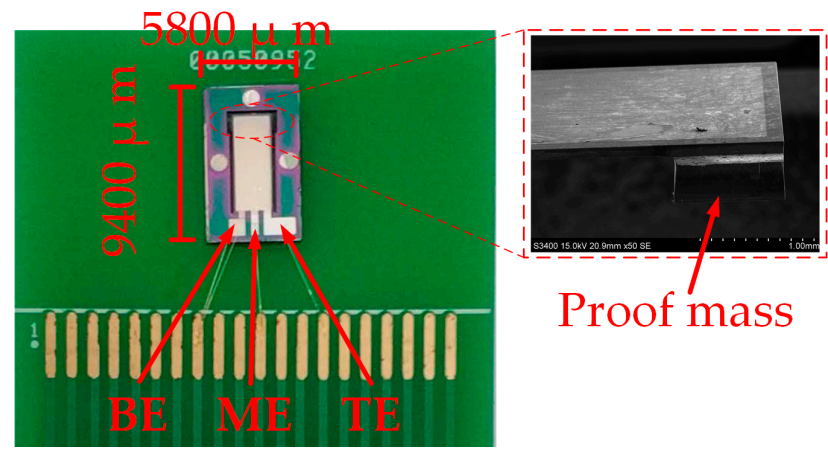

Figure 5. Photograph of packaged acceleration sensor chip.

\section{Results and Discussion}

\subsection{XRD and XPS Analysis}

To determine the composition and chemical structure of the LZO thin film, XRD (AXS D8 ADVANCE, Bruker Corporation, Karlsruhe, Germany) and XPS (PHI 5700 ESCA System, Physical Electronics Co., Chanhassen, MN, USA) were used for analysis. LZO thin film samples were prepared on the $\mathrm{Pt} / \mathrm{Ti} / \mathrm{SiO}_{2} / \mathrm{Si}$ substrate with the same fabrication parameters as the chips.

Figure 6 shows the XRD spectra of the pure $\mathrm{ZnO}$ and $\mathrm{LZO}$ thin film. The (002) peaks of $\mathrm{ZnO}$, LZO, Pt (111), and Pt (200) peaks can all be observed. The (002) peak of pure $\mathrm{ZnO}$ is higher than that of $\mathrm{LZO}$; this can be attributed to $\mathrm{Li}$ substituting for $\mathrm{Zn}$ atoms. Because of the small radius of $\mathrm{Li}$ atoms, the crystallinity of the $\mathrm{ZnO}$ thin film decreased, and reducing the peak of $\mathrm{ZnO}$ in $5 \mathrm{wt} \%$ LZO decreased. The comparison of $\mathrm{ZnO}$ peaks between pure $\mathrm{ZnO}$ and $5 \mathrm{wt} \% \mathrm{LZO}$ was given in the inset. The peak of $\mathrm{ZnO}(002)$ of the pure $\mathrm{ZnO}$ sample appeared at $34.42^{\circ}$, and the peak of $\mathrm{ZnO}(002)$ of LZO shifted to the right by $0.19^{\circ}$ to $34.61^{\circ}$. The substitution impurity of the small atomic radius of $\mathrm{Li}^{+}$caused the decrease of lattice constant and produced compressive stress inside the LZO thin film, which led to the peak shift to the larger angle [38]. The $\mathrm{ZnO}$ thin film likely contained defects inside, such as $\mathrm{V}_{\mathrm{o}}$ (Oxygen vacancy) and $\mathrm{Zn}_{\mathrm{i}}$ (Zinc interstitial atom), which makes the $\mathrm{ZnO}$ films usually 
n-type semiconductors. After Li-doping, Li atoms as acceptor impurities increased the resistivity of the $\mathrm{ZnO}$ film, thereby enhancing the piezoelectric properties.

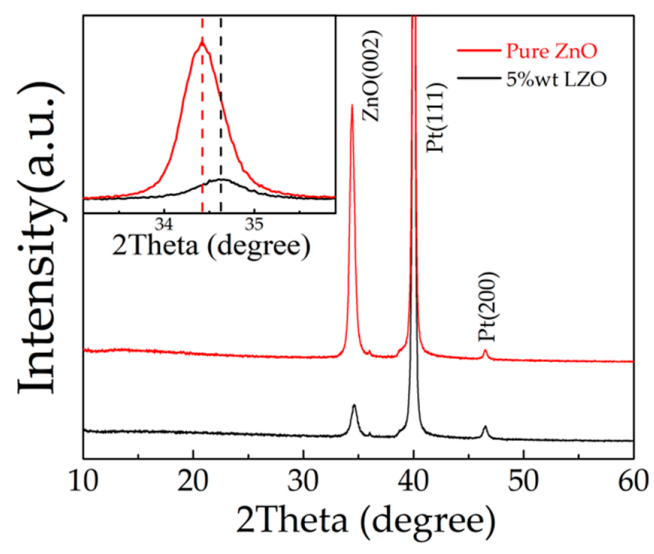

Figure 6. XRD spectra of the LZO thin film (inset shows (002) peaks of pure $\mathrm{ZnO}$ and $5 \mathrm{wt} \% \mathrm{LZO}$ ).

Figure 7 shows the chemical bonding states of the LZO thin film by XPS, with a scan range from 0 to $1350 \mathrm{eV}$. The binding energies were calibrated via the $\mathrm{C} 1 \mathrm{~s}$ peak. The presence of $\mathrm{Zn}$ and $\mathrm{O}$ is confirmed in Figure 7a. The binding energy of Zn 2p3/2 and Zn 2p1/2 was found at 1021.9 and 1048.9. It is proved that $\mathrm{Zn}$ ions exist in the state of $\mathrm{Zn}^{2+}$ in the $\mathrm{LZO}$ thin film $[39,40]$. In the narrow scan of XPS spectra (Figure 7b), Li 1s spectra can be fitted into two different peaks, located at 54.1 and $55.8 \mathrm{eV}$, respectively. The peak at $54.1 \mathrm{eV}$ was attributed to $\mathrm{Li}$ interstitial $\left(\mathrm{Li}_{\mathrm{i}}\right)$ defects corresponding to the valence state of unentire oxidation. Another $\mathrm{Li} 1 \mathrm{~s}$ peak, located at $55.8 \mathrm{eV}$, was related to the $\mathrm{Li}-\mathrm{O}$ bond, which confirms the substitution of $\mathrm{Li}^{+}$at the $\mathrm{Zn}^{2+}$ site $\left(\mathrm{Li}_{\mathrm{Zn}}\right)$ [41-43].

This coincides with the core level of $\mathrm{Li} 1 \mathrm{~s}[44,45]$, indicating that $\mathrm{Li}^{+}$exists in the $\mathrm{LZO}$ thin film.
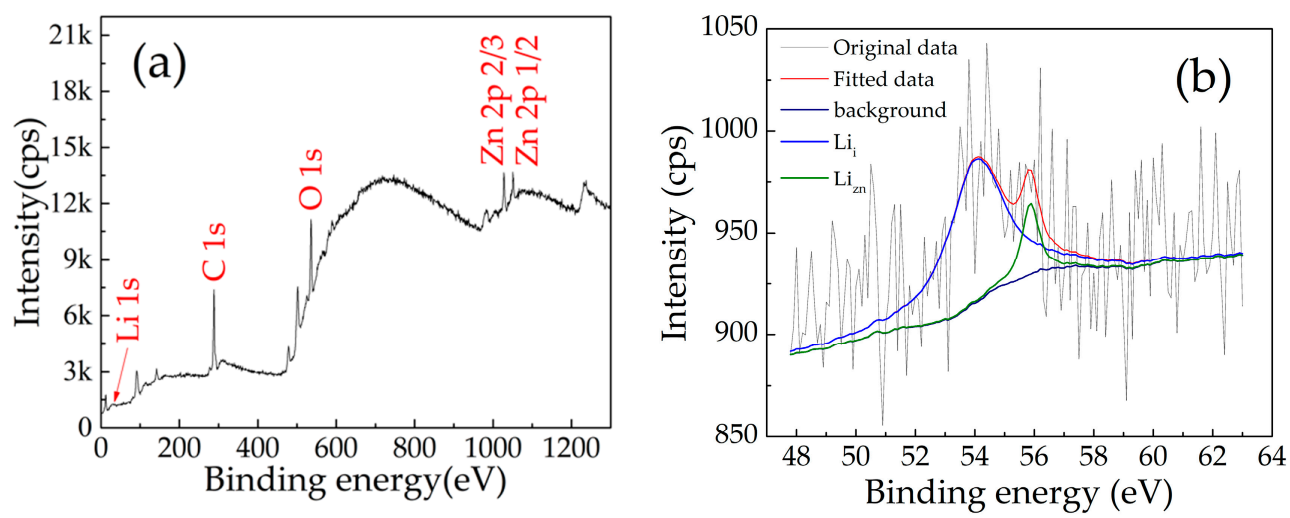

Figure 7. XPS spectra of the LZO thin film: (a) Full range; (b) narrow scan.

\subsection{AFM and SEM Analysis}

In order to study the surface morphology of the LZO thin film, samples were prepared as above and characterized by atomic force microscopy (AFM) (Innova, Bruker Corporation, Karlsruhe, Germany). Figure 8 shows the AFM images of the LZO thin film. The average grain size of the LZO film was about $113.7 \mathrm{~nm}$ and the roughness was $100 \mathrm{~nm}$ (all measured by AFM). A scanning electron microscope (SEM) was used to characterize a cross-section of the multilayered structure (SU8010, Hitachi, Tokyo, Japan). From Figure 9, it can be seen that the LZO film grew along the $c$-axis direction and showed a columnar structure. The particle size of the two LZO thin films coincided with the results obtained by AFM. The thicknesses of the TE, LZO II, ME, LZO I, BE, Ti layer, and $\mathrm{SiO}_{2}$ layer, approximately measured by SEM, are shown in Figure 9. 

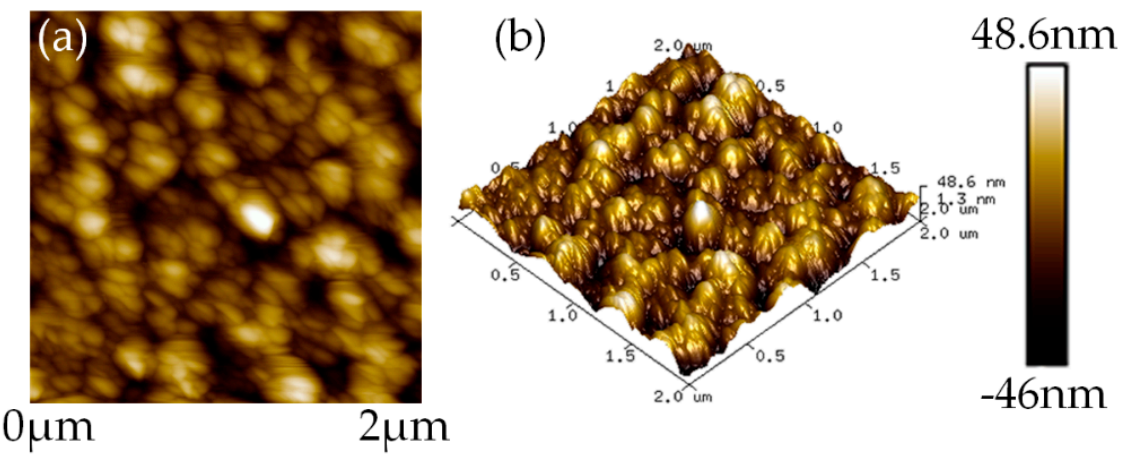

Figure 8. Atomic force microscopy (AFM) images of the LZO thin film: (a) Surface morphology; (b) 3D surface topography.

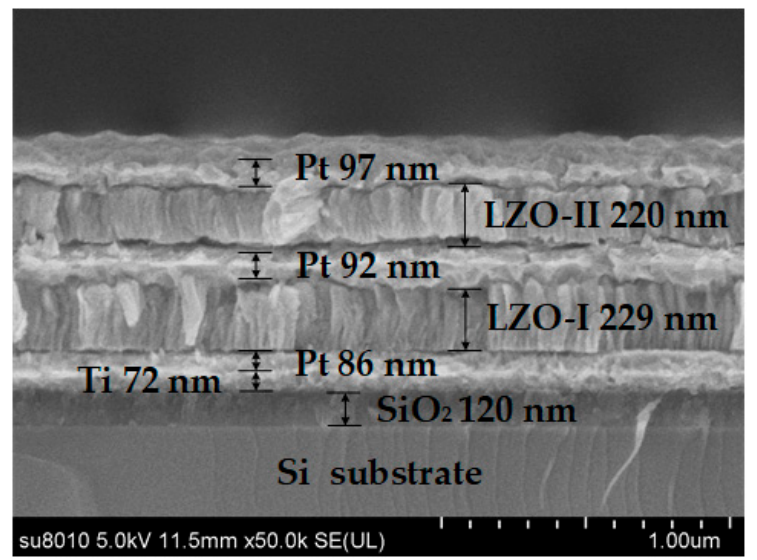

Figure 9. Scanning electron microscope (SEM) cross-section image of the sensor.

In order to study the piezoelectric properties of pure $\mathrm{ZnO}$ and $\mathrm{LZO}$ thin films, piezoelectric force microscopy (PFM, Bruker Multimode 8, Billerica, MA, USA) was used to measure the piezoelectric constant $d_{33}$ of pure $\mathrm{ZnO}$ and $\mathrm{LZO}$ thin films. The deformation of the thin films was measured by applying voltage at both ends. As shown in Figure 10, with the increase of applied voltage in the range of 0 to $10 \mathrm{~V}$, the displacement of $\mathrm{ZnO}$ thin films increased in the range from $16.8 \mathrm{pm}$ to $114.3 \mathrm{pm}$, and that of LZO films increased in the range from $36.9 \mathrm{pm}$ to $170.3 \mathrm{pm}$. The two curves were fitted linearly, and the slope of the fitted line was piezoelectric coefficient $d_{33}$. We could see that the $d_{33}$ of LZO thin films was $13.96 \mathrm{pm} / \mathrm{V}$, which is higher than that of $\mathrm{ZnO} 10.43 \mathrm{pm} / \mathrm{V}$, and the enhancement percentage is $33.84 \%$. This proves that the piezoelectric properties of $\mathrm{ZnO}$ films can be improved by introducing Li as an impurity.

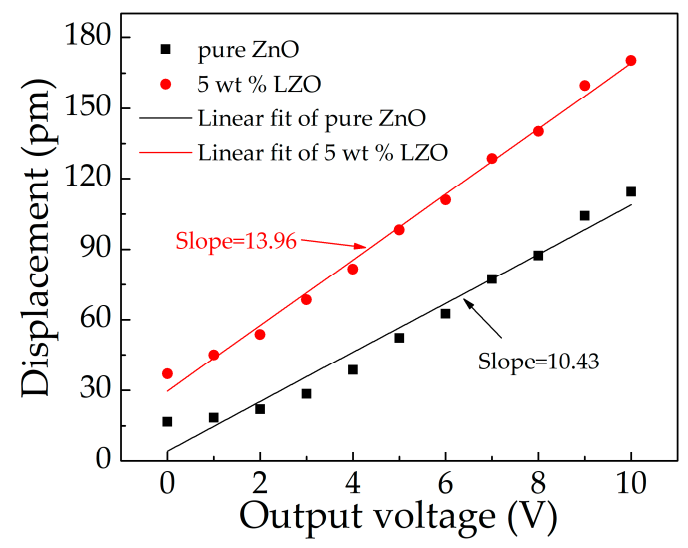

Figure 10. Piezoelectric characteristic of pure $\mathrm{ZnO}$ and $5 \mathrm{wt} \% \mathrm{LZO}$. 


\subsection{Sensitivity of the Proposed Sensor}

The testing system of the proposed acceleration sensor consisted of a standard vibrator (Dongling ESS-050, Dongling Vibration Test Instrument Co., Ltd, Suzhou, China), multimeter (Agilent 34401A, Agilent Technologies Inc., Santa Clara, CA, USA), and computer. The system can be tested for vibration and sensitivity characteristics with an exciting frequency from 50 to 20,000 Hz and acceleration from 0 to $30 \mathrm{~g}$, and the test data can be automatically acquired, as shown in Figure 11.

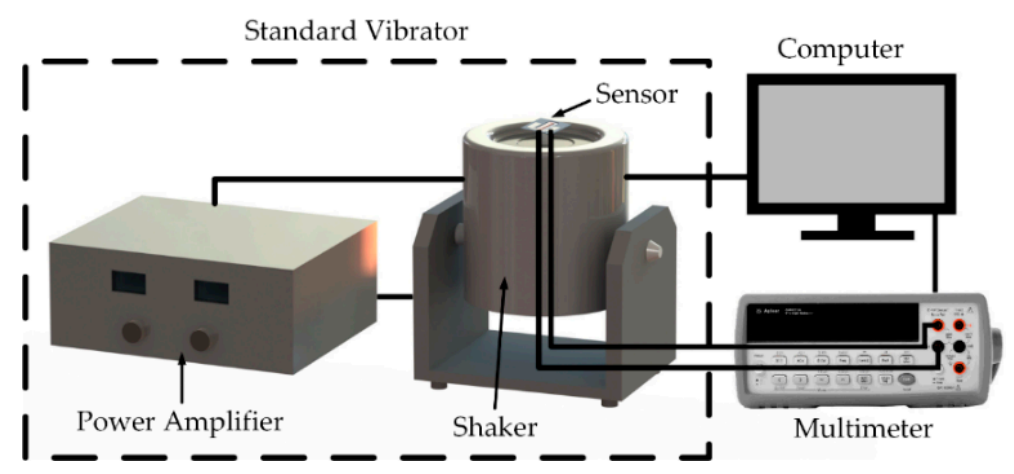

Figure 11. Testing system of acceleration sensor.

The response frequency characteristics of the sensor were tested by the frequency sweep mode of the standard vibrator. The sweep range of excitation frequency was from 50 to $2000 \mathrm{~Hz}$ under a $1 \mathrm{~g}$ acceleration. The acceleration sensor was rigidly fixed on the vibrator, the BE and TE of the sensor were connected to the multimeter, acceleration acted on the sensor along the $z$-axis, and the output voltage $\left(V_{\text {out2 }}\right)$ of the sensor was collected in real time. In a certain excitation frequency range, the relationship between excitation frequency and $V_{\text {out2 }}$ was studied. When the applied frequency reached a certain value, the resonance effect occurred in the cantilever beam structure, and accordingly, the output voltage could reach the maximum value. Figure 12a shows the relationship curve between output voltage and excitation frequency under an acceleration of $1 \mathrm{~g}$. When the excitation frequency reached $1363 \mathrm{~Hz}, V_{\text {out2 }}$ reached the maximum value of $46.3 \mathrm{mV}$, and only one obvious peak was observed, which meant that only the first mode existed in the scanning frequency range. The results show that the resonance frequency of the fabricated cantilever beam structure was $1363 \mathrm{~Hz}$. This is close to the simulation results of $1327.7 \mathrm{~Hz}$, but there are deviations. The main reasons are as follows: (1) In the fabrication process of the cantilever beam, the uniformity of ICP etching had errors, which resulted in the uneven thickness of the cantilever beam and changed the resonance frequency; (2) although the total thickness of the multi-layer structure on the cantilever beam was much thinner than the thickness of the cantilever beam, it still affected the resonance frequency of the cantilever beam.
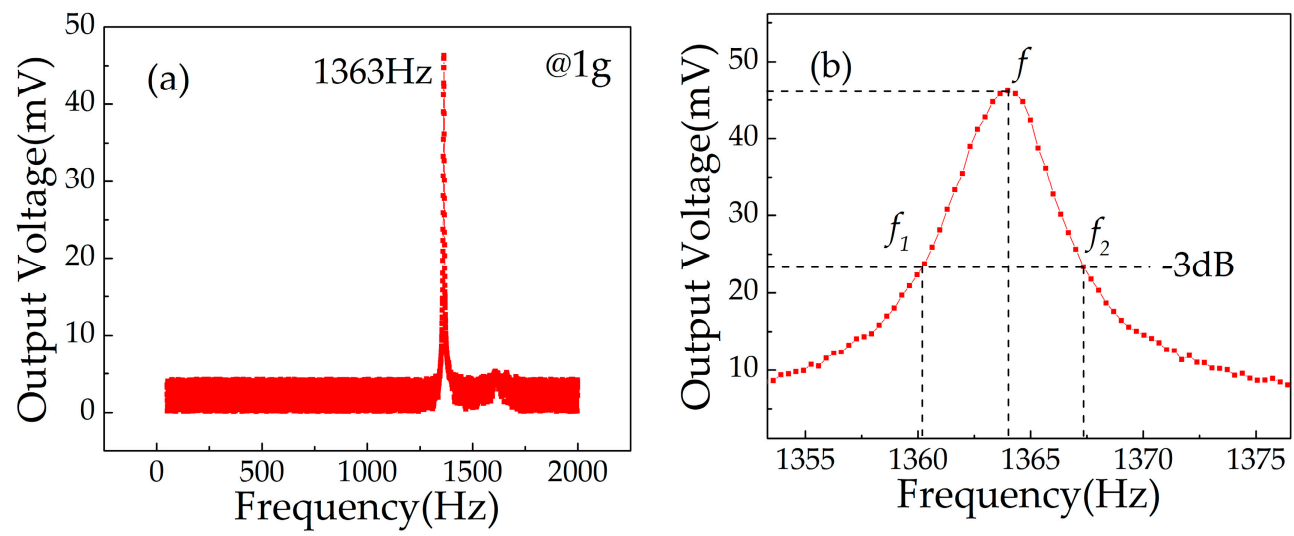

Figure 12. Relationship curve between output voltage and excitation frequency: (a) resonant frequency; (b) quality factor. 
The quality factor $Q$ represents the energy dissipated by the body in overcoming the internal friction in resonance.

$$
Q=2 \pi \frac{E_{s}}{E_{c}}=\frac{f}{f_{1}-f_{2}}
$$

where $E_{s}$ is the mechanical energy stored by the oscillator in the resonant state, and $E_{c}$ is the energy dissipated by the oscillator in the resonant state every cycle, $\mathrm{f}$ is the resonance frequency and $f_{1}, f_{2}$ is the half power point frequency $(-3 \mathrm{~dB})$. From Figure $2 b$, we can estimate that $Q$ is 309.5.

The output voltage characteristics of the double and single piezoelectric layers were measured by applying $0.2-2.2 \mathrm{~g}$ acceleration $(0.2 \mathrm{~g}$ increment) along the $z$-axis direction of the sensor at resonance frequency $(1363 \mathrm{~Hz})$. As shown in Figure 13, with the increase of applied acceleration, $V_{\text {out }}$ increased from $6.05 \mathrm{mV}$ to $58.59 \mathrm{mV}$, and $V_{\text {out2 }}$ increased from $13.8 \mathrm{mV}$ to $81.2 \mathrm{mV}$. The slopes of fitting lines represent the sensitivity of the sensor. $S_{d}$ and $S_{s}$ were $33.08 \mathrm{mV} / \mathrm{g}$ and $26.05 \mathrm{mV} / \mathrm{g}$, respectively. The sensitivity of the double LZO thin film structure was higher than that of the single LZO thin film structure, but it was not twice as large as the single LZO thin film. This is because the thickness of the LZO I film was not equal to that of the LZO II in the process of thin film preparation, so it was not consistent with the conclusion of Equation (11) in the ideal state.

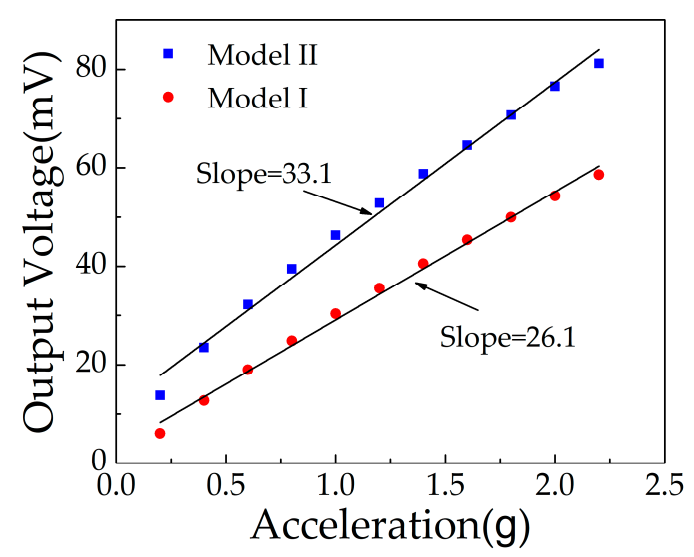

Figure 13. Output voltage of sensor working in model I and model II.

The output voltage of the sensor below the resonance frequency, in the range from $0.2 \mathrm{~g}$ to $2.2 \mathrm{~g}$, is given in Figure 14. The sensitivity was reduced with decreased excitation frequency. Under the applied frequency of $1361 \mathrm{~Hz}, 1359 \mathrm{~Hz}, 1357 \mathrm{~Hz}$, and $1355 \mathrm{~Hz}$, the sensitivity was $30.6 \mathrm{mV} / \mathrm{g}, 18.5 \mathrm{mV} / \mathrm{g}$, $14.4 \mathrm{mV} / \mathrm{g}$, and $8.5 \mathrm{mV} / \mathrm{g}$, respectively. With the decrease of excitation frequency, the resonance effect of the cantilever beam was weakened, resulting in reduced deformation. From Figure 15, we can see that the sensitivity was approximately linear with the excitation frequency, in the range from $1351 \mathrm{~Hz}$ to $1363 \mathrm{~Hz}$.

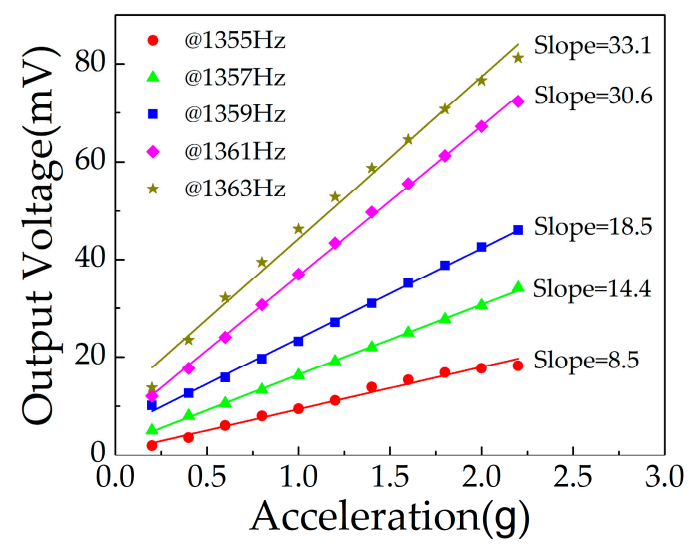

Figure 14. Output voltage of the sensor below resonance frequency. 


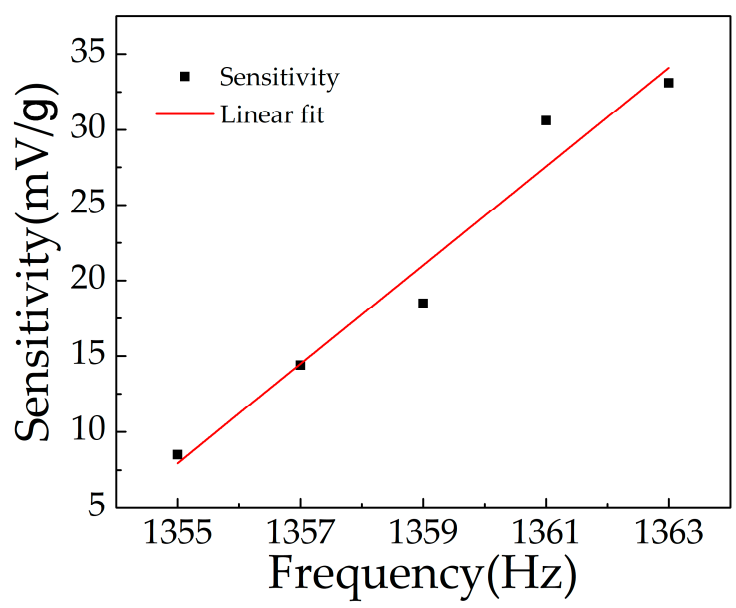

Figure 15. Sensitivity of the sensor in the range from $1355 \mathrm{~Hz}$ to $1363 \mathrm{~Hz}$.

\section{Conclusions}

In summary, this paper presents an acceleration sensor with a double piezoelectric layer structure based on the piezoelectric effect of the Li-doped $\mathrm{ZnO}$ thin film. Two models of single and double piezoelectric layers were established and compared. It is concluded that, in theory, the voltage sensitivity of the double piezoelectric layer should be twice that of the single piezoelectric layer. The multilayer structure was fabricated on a Si cantilever beam with a proof mass by using MEMS technology, and the ME was introduced for comparative testing. The test results show that the sensor can achieve maximum output at resonance frequency, and $S_{d}$ is higher than $S_{s}$. It proves that the designed double piezoelectric layer structure can improve the output sensitivity of the acceleration sensor.

Author Contributions: C.A. and X.Z. wrote the manuscript; X.Z. and D.W. designed the project; C.A., Y.B., Y.L., and S.L. performed the experiments; C.A. and X.Z. contributed to the data analysis.

Funding: This research was supported by the National Natural Science Foundation of China (No. 61471159), Basic Scientific Research Project of the Provincial Higher University in Heilongjiang Province (KJCXZD201705), Young Scholars with Creative Talents in Heilongjiang Province (No. 2015018) and Special Funds for Science and Technology Innovation Talents of Harbin in China (No. 2016RAXXJ016).

Conflicts of Interest: The authors declare no conflict of interest.

\section{References}

1. Shipway, A.N.; Katz, E.; Willner, I. Nanoparticle Arrays on Surfaces for Electronic, Optical, and Sensor Applications. ChemPhysChem 2000, 1, 18-52. [CrossRef]

2. Wang, Z.L. Triboelectric nanogenerators as new energy technology and self-powered sensors - principles, problems and perspectives. Faraday Discuss. 2014, 176, 447-458. [CrossRef] [PubMed]

3. Aravamudhan, S.; Bhansali, S. Reinforced piezoresistive pressure sensor for ocean depth measurements. Sens. Actuator A 2008, 142, 111-117. [CrossRef]

4. Zhao, X.; Wang, Y.; Wen, D. Fabrication and Characteristics of a SOI Three-Axis Acceleration Sensor Based on MEMS Technology. Micromachines 2019, 10, 238. [CrossRef]

5. Li, Y.; Efatmaneshnik, M.; Dempster, A.G. Attitude determination by integration of MEMS inertial sensors and GPS for autonomous agriculture applications. GPS Solut. 2011, 16, 41-52. [CrossRef]

6. Jing, Z.; Li, J.; Zhang, X.; Feng, K.; Zheng, T. A Novel Rotation Scheme for MEMS IMU Error Mitigation Based on a Missile-Borne Rotation Semi-Strapdown Inertial Navigation System. Sensors 2019, 19, 1683. [CrossRef]

7. Simanjuntak, F.M.; Ohno, T.; Samukawa, S. Neutral Oxygen Beam Treated ZnO-Based Resistive Switching Memory Device. ACS Appl. Electron. Mater. 2018, 1, 18-24. [CrossRef]

8. Ganji, B.A.; Nateri, M.S.; Dardel, M. Design and modeling of a novel high sensitive MEMS piezoelectric vector hydrophone. Microsyst. Technol. 2018, 24, 2085-2095. [CrossRef]

9. te Lindert, B.H.; Van Someren, E.J. Sleep estimates using microelectromechanical systems (MEMS). Sleep 2013, 36, 781-789. [CrossRef] [PubMed] 
10. Lenoir, B.; Lévy, A.; Foulon, B.; Lamine, B.; Christophe, B.; Reynaud, S. Electrostatic accelerometer with bias rejection for gravitation and Solar System physics. Adv. Space Res. 2011, 48, 1248-1257. [CrossRef]

11. Gesing, A.L.; Alves, F.D.P.; Paul, S.; Cordioli, J.A. On the design of a MEMS piezoelectric accelerometer coupled to the middle ear as an implantable sensor for hearing devices. Sci Rep 2018, 8, 3920. [CrossRef]

12. Mahmood, M.S.; Celik-Butler, Z.; Butler, D.P. Design, fabrication and characterization of flexible MEMS accelerometer using multi-Level UV-LIGA. Sens. Actuator A 2017, 263, 530-541. [CrossRef]

13. Raaja, B.P.; Daniel, R.J.; Sumangala, K. A Simple Analytical Model for MEMS Cantilever Beam Piezoelectric Accelerometer and High Sensitivity Design for SHM (structural health monitoring) Applications. Trans. Electr. Electron. Mater. 2017, 18, 78-88. [CrossRef]

14. Shi, Y.; Zhao, Y.; Feng, H.; Cao, H.; Tang, J.; Li, J.; Zhao, R.; Liu, J. Design, fabrication and calibration of a high-G MEMS accelerometer. Sens. Actuator A 2018, 279, 733-742. [CrossRef]

15. Kumar, V.; Jafari, R.; Pourkamali, S. Ultra-Low Power Digitally Operated Tunable MEMS Accelerometer. IEEE Sens. J. 2016, 16, 8715-8721. [CrossRef]

16. Kim, K.J.; Park, Y.R. Large and abrupt optical band gap variation in In-doped ZnO. Appl. Phys. Lett. 2001, 78, 475-477. [CrossRef]

17. Wang, M.; Ren, F.; Zhou, J.; Cai, G.; Cai, L.; Hu, Y.; Wang, D.; Liu, Y.; Guo, L.; Shen, S. N Doping to ZnO Nanorods for Photoelectrochemical Water Splitting under Visible Light: Engineered Impurity Distribution and Terraced Band Structure. Sci. Rep. 2015, 5, 12925. [CrossRef]

18. Wong, Y.-R.; Yuan, Y.; Du, H.; Xia, X. Development of high sensitivity, large frequency bandwidth ZnO-based accelerometers. Sens. Actuator A 2015, 229, 23-29. [CrossRef]

19. Boyadjiev, S.I.; Georgieva, V.; Yordanov, R.; Raicheva, Z.; Szilágyi, I.M. Preparation and characterization of ALD deposited ZnO thin films studied for gas sensors. Appl. Surf. Sci. 2016, 387, 1230-1235. [CrossRef]

20. Joshi, S.; Parmar, M.; Rajanna, K. A novel gas flow sensing application using piezoelectric ZnO thin films deposited on Phynox alloy. Sens. Actuator A 2012, 187, 194-200. [CrossRef]

21. Sudha, M.; Radha, S.; Kirubaveni, S.; Kiruthika, R.; Govindaraj, R.; Santhosh, N. Experimental study on structural, optoelectronic and room temperature sensing performance of Nickel doped $\mathrm{ZnO}$ based ethanol sensors. Solid State Sci. 2018, 78, 30-39. [CrossRef]

22. Cho, K.-S.; Kim, D.-H.; Kim, Y.-H.; Nah, J.; Kim, H.-K. Li-doped $\mathrm{Cu}_{2} \mathrm{O} / \mathrm{ZnO}$ heterojunction for flexible and semi-transparent piezoelectric nanogenerators. Ceram. Int. 2017, 43, 2279-2287. [CrossRef]

23. Kim, D.; Lee, K.Y.; Gupta, M.K.; Majumder, S.; Kim, S.-W. Self-Compensated Insulating ZnO-Based Piezoelectric Nanogenerators. Adv. Funct. Mater. 2014, 24, 6949-6955. [CrossRef]

24. Zhang, Y.; Yan, X.; Yang, Y.; Huang, Y.; Liao, Q.; Qi, J. Scanning probe study on the piezotronic effect in ZnO nanomaterials and nanodevices. Adv. Mater. 2012, 24, 4647-4655. [CrossRef]

25. Zhang, Y.; Liu, C.; Liu, J.; Xiong, J.; Liu, J.; Zhang, K.; Liu, Y.; Peng, M.; Yu, A.; Zhang, A.; et al. Lattice Strain Induced Remarkable Enhancement in Piezoelectric Performance of ZnO-Based Flexible Nanogenerators. ACS Appl. Mater. Interfaces 2016, 8, 1381-1387. [CrossRef]

26. Simanjuntak, F.M.; Pattanayak, B.; Lin, C.-C.; Tseng, T.-Y. Resistive Switching Characteristics of Hydrogen Peroxide Surface Oxidized ZnO-based Transparent Resistive Memory Devices. ECS Trans. 2017, 77, 155-160. [CrossRef]

27. Zhao, X.; Li, Y.; Ai, C.; Wen, D. Resistive Switching Characteristics of Li-Doped ZnO Thin Films Based on Magnetron Sputtering. Materials 2019, 12, 1282. [CrossRef]

28. Kim, H.C.; Song, S.; Kim, J. Fabrication of a Miniaturized ZnO Nanowire Accelerometer and Its Performance Tests. Sensors 2016, 16, 1499. [CrossRef]

29. Li, S.; Zhao, X.; Bai, Y.; Li, Y.; Ai, C.; Wen, D. Fabrication Technology and Characteristics Research of the Acceleration Sensor Based on Li-Doped ZnO Piezoelectric Thin Films. Micromachines 2018, 9, 178. [CrossRef]

30. Pan, Z.; Zhao, X.; Peng, W.; Qi, X.; He, Y. A ZnO-Based Programmable UV Detection Integrated Circuit Unit. IEEE Sens. J. 2016, 16, 7919-7923. [CrossRef]

31. Wang, Y.-H.; Song, P.; Li, X.; Ru, C.; Ferrari, G.; Balasubramanian, P.; Amabili, M.; Sun, Y.; Liu, X. A Paper-Based Piezoelectric Accelerometer. Micromachines 2018, 9, 19. [CrossRef]

32. Zou, Q.; Tan, W.; Kim, E.S.; Loeb, G.E. Single- and Triaxis Piezoelectric-Bimorph Accelerometers. J. Microelectromech. Syst. 2008, 17, 45-57. [CrossRef] 
33. Nagano, T.; Nishigaki, M.; Itaya, K.; Kawakubo, T. Optimization of Deposition Process and Microscopic Characterization of Highly Oriented Aluminum Nitride Thin Films for Bimorph Structures of Piezoelectric Tunable Capacitors. Jpn. J. Appl. Phys. 2009, 48, 021402. [CrossRef]

34. Kanda, K.; Hirai, S.; Fujita, T.; Maenaka, K. Piezoelectric MEMS with multilayered $\mathrm{Pb}(\mathrm{Zr}, \mathrm{Ti}) \mathrm{O}_{3}$ thin films for energy harvesting. Sens. Actuator A 2018, 281, 229-235. [CrossRef]

35. Shih, W.Y.; Li, X.; Gu, H.; Shih, W.-H.; Aksay, I.A. Simultaneous liquid viscosity and density determination with piezoelectric unimorph cantilevers. J. Appl. Phys. 2001, 89, 1497-1505. [CrossRef]

36. Shen, D.; Park, J.-H.; Noh, J.H.; Choe, S.-Y.; Kim, S.-H.; Wikle, H.C.; Kim, D.-J. Micromachined PZT cantilever based on SOI structure for low frequency vibration energy harvesting. Sens. Actuator A 2009, 154, 103-108. [CrossRef]

37. Shen, D.; Park, J.-H.; Ajitsaria, J.; Choe, S.-Y.; Wikle, H.C.; Kim, D.-J. The design, fabrication and evaluation of a MEMS PZT cantilever with an integrated Si proof mass for vibration energy harvesting. J. Micromech. Microeng. 2008, 18, 055017. [CrossRef]

38. Song, M.; Liu, Y.; Yu, A.; Zhang, Y.; Zhai, J.; Wang, Z.L. Flexible Li-doped ZnO piezotronic transistor array for in-plane strain mapping. Nano Energy 2019, 55, 341-347. [CrossRef]

39. Jeong, S.H.; Park, B.N.; Lee, S.B.; Boo, J.H. Study on the doping effect of Li-doped ZnO film. Thin Solid Films 2008, 516, 5586-5589. [CrossRef]

40. Song, X.; Wu, Y.; Cai, F.; Pan, D.; Xiao, G. High-efficiency and low-cost Li/ZnO catalysts for synthesis of glycerol carbonate from glycerol transesterification: The role of $\mathrm{Li}$ and $\mathrm{ZnO}$ interaction. Appl. Catal. A 2017, 532, 77-85. [CrossRef]

41. Ghosh, S.; Khan, G.G.; Mandal, K.; Thapa, S.; Nambissan, P.M.G. Positron annihilation studies of vacancy-type defects and room temperature ferromagnetism in chemically synthesized Li-doped $\mathrm{ZnO}$ nanocrystals. $J$. Alloys Compd. 2014, 590, 396-405. [CrossRef]

42. Lu, J.G.; Zhang, Y.Z.; Ye, Z.Z.; Zeng, Y.J.; He, H.P.; Zhu, L.P.; Huang, J.Y.; Wang, L.; Yuan, J.; Zhao, B.H.; et al. Control of p- and n-type conductivities in Li-doped ZnO thin films. Appl. Phys. Lett. 2006, 89, 112113. [CrossRef]

43. Dupin, J.-C.; Gonbeau, D.; Vinatier, P.; Levasseur, A. Systematic XPS studies of metal oxides, hydroxides and peroxides. Phys. Chem. Chem. Phys. 2000, 2, 1319-1324. [CrossRef]

44. Bhattacharjee, R.; Hung, I.M. Effect of different concentration Li-doping on the morphology, defect and photovoltaic performance of $\mathrm{Li}-\mathrm{ZnO}$ nanofibers in the dye-sensitized solar cells. Mater. Chem. Phys. 2014, 143, 693-701. [CrossRef]

45. Manivannan, V.; Chennabasappa, M.; Garrett, J. Optimization and Characterization of Lithium Ion Cathode Materials in the System $(1-\mathrm{x}-\mathrm{y}) \mathrm{LiNi}_{0.8} \mathrm{Co}_{0.2} \mathrm{O}_{2} \bullet \mathrm{xLi}_{2} \mathrm{MnO}_{3} \bullet \mathrm{yLiCoO}_{2}$. Energies 2010, 3, 847-865. [CrossRef] 